\title{
Archivos de infelicidad en la ficción realista: el fracaso del sueño americano en Pastoral Americana y Flesh and Blood ${ }^{*}$
}

\author{
Unhappy Archives in Realist Fiction: the Failure of the American Dream \\ in American Pastoral and Flesh and Blood
}

\author{
Mariela Solana \\ mariela.solana@gmail.com \\ Profesora \\ Universidad Nacional Arturo Jauretche \\ Del Barco Centenera 652 5to "b" \\ CP: 1424 - Capital Federal \\ Argentina
}

\section{Resumen}

En este artículo se analizan las novelas Pastoral Americana, de Philip Roth, y Flesh and Blood, de Michael Cunningham, con el objetivo de rastrear el mapa afectivo que emerge a fines de los años 1960 y principios de los 1970 en Estados Unidos una vez que la promesa de felicidad —vinculada a la búsqueda del sueño americano- pierde validez como garante de cohesión intergeneracional. Para eso, se utilizan como marco teórico las reflexiones de Hayden White en torno a la literatura testimonial y ciertos desarrollos recientes provenientes del llamado giro afectivo. En este artículo se concluye que el valor de esas novelas radica en que ilustran la historicidad de la experiencia de esa época a la vez que habilitan la reflexión sobre el ideal de felicidad en relación con sus asociaciones nacionales, raciales y sexuales y en relación con la noción de contingencia.

\section{Palabras clave}

Literatura; Historicidad; Novela histórica.

\begin{abstract}
In this paper we explore the novels American Pastoral, by Philip Roth, and Flesh and Blood, by Michael Cunningham, in order to trace the affective mapping that emerges in the late $1960 \mathrm{~s}$ and early 1970s in the United States, once the promise of happiness - linked to the American dream - loses its value as an intergenerational cement. The theoretical framework employed includes Hayden White's considerations on witness literature and recent work by affective turn theorists. This article claims that the value of these novels lies not only in their ability to picture the historicity of the experience of that time, but also in their ability to rethink the ideal of happiness in relation to national, racial and sexual beliefs, and in relation to the notion of contingency.
\end{abstract}

\section{Keywords}

Literature; Historicity; Historical Novel.

Recibido el: 3/8/2014

Aprobado el: 26/9/2014

\footnotetext{
${ }^{*}$ Investigación financiada por el Consejo Nacional de Investigaciones Científicas y Técnicas - CONICET.
} 
Todas las familias felices se parecen, pero las infelices lo son cada una a su manera.

Leon Tolstoi, Anna Karenina

"Y vivieron felices para siempre". Con esta frase breve pero contundente solían cerrarse muchas de las historias que poblaron nuestra niñez. El camino para alcanzar esa felicidad eterna, sin embargo, no era fácil. Los personajes debían sortear todo tipo de dificultades y superar todo tipo de penurias. Pero era sabido que el calvario iba a terminar y que el tesoro al final del arcoíris sería la tan añorada felicidad. La felicidad, no sólo en la literatura infantil, sino en distintas expresiones del pensamiento occidental, suele presentarse como el fin último de la vida, como el objeto al que todo ser humano debe aspirar, como aquello que da sentido a las acciones del presente en vistas a un futuro mejor.

En este artículo, se analizan dos novelas en las antípodas de los cuentos infantiles: Pastoral Americana, de Philip Roth, y Flesh and Blood, de Michael Cunningham. Ambos relatos pueden ser considerados como puestas en escena del choque intergeneracional en el seno familiar una vez que el ideal de vida feliz, que funcionó como principio regulador de la vida de los padres, es repudiado y abandonado por los hijos. Ambas novelas ponen en primer plano las tragedias que acontecen a dos familias - los Levov y los Stavos - tras el desgaste de la fantasía del sueño americano a fines de los años 1960 y principios de los 1970.

El interés por examinar esas novelas es doble. Por un lado, se parte de la literatura para rastrear el componente afectivo de la conciencia histórica de ruptura intergeneracional de la segunda mitad del siglo XX norteamericano. Ambas narraciones, tal como se argumentará, pueden ser consideradas mapas afectivos que permiten echar luz sobre el clima emocional asociado a la caída de cierto ideal de felicidad en un momento histórico de ruptura. Por otro lado, se busca ver las novelas como algo más que un mero índice histórico. Así, se intenta demostrar que ambos relatos permiten comprender más cabalmente cómo funciona la promesa de felicidad, es decir, qué tipo de universo semántico surge una vez que la felicidad es invocada. La literatura de Roth y Cunningham abre un abanico de sentidos en torno a la felicidad que permite identificar, en primer lugar, sus asociaciones respecto al género, la religión y la nación y, en segundo lugar, su rol como repelente de las contingencias e improbabilidades.

Para llevar a cabo esa interpretación, el artículo parte de la filosofía de la historia de Hayden White -en especial de su reivindicación de la literatura testimonial como productora de saberes sobre el pasado- en sintonía con algunos desarrollos recientes provenientes del giro afectivo.

\section{La dimensión histórica de la ficción realista}

Una puerta de entrada para pensar la relación entre literatura e historia es la filosofía de la historia de Hayden White. Eso es así porque permite comprender tanto la necesidad de la historia profesional de separarse y diferenciarse de la literatura, como la imposibilidad de un quiebre sustancial entre ambos tipos de representaciones. 
Si bien este artículo no pretende indagar sobre la diferencia específica entre historia y literatura, es relevante recordar, tal como lo hace White, que a comienzos del siglo XIX la disciplina histórica se profesionalizó, adjudicándose la tarea de describir la manera en que las cosas habían sido realmente en lugar de la manera en que debían de haber sido (WHITE 2010b). Esto último quedó en manos de la literatura y cualquier intrusión de lo ficcional en el discurso histórico pasó a ser visto como un ataque a la objetividad y a la cientificidad de la nueva disciplina histórica.

A pesar de que, actualmente, el estatus científico de la historia ha sido cuestionado, White señala que todavía existen resistencias a la hora de entender el discurso histórico como una narración. Eso es claro, por ejemplo, en aquellos intentos de disociar el contenido fáctico del texto histórico de su forma literaria con el objetivo de evaluar su valor veritativo. White, en cambio, pone en duda la férrea dicotomía entre la dimensión literal y la figural, señalando que ambas deberían ser consideradas "como los polos de un continuum lingüístico, entre los cuales debe moverse el habla para la articulación de cualquier discurso serio o frívolo" (WHITE 2003, p. 170).

White no se detiene en ese punto. En sus escritos de los últimos tiempos, el filósofo sostiene que, lejos de tergiversar los hechos que acontecieron, la literatura puede ofrecer un tratamiento especial de los eventos históricos que enriquece y profundiza nuestra comprensión del pasado. La literatura, de ese modo, puede ser pensada como una herramienta legítima para producir saberes 158 en torno a lo que ha sido; una herramienta que, en ocasiones, supera incluso a la historia profesional.

Ese último punto es evidente cuando White analiza, por ejemplo, la obra de Primo Levi. White sostiene que, a pesar de que Levi haya pretendido escribir un tratado científico sobre su experiencia en los campos, su mérito radica en "la artisticidad (por medio de lo cual me refiero a artefactos literarios, poéticos y retóricos) que emplea para evocar una imagen persuasiva de un cosmos completamente horroroso" (WHITE 2010a, p. 171). La potencia de Si esto es un hombre estriba ya no en su anhelo explícito de depurar el lenguaje de giros retóricos - anhelo que, como lo demuestra White, se ve constantemente frustrado por el uso de tropos y figuras-, sino, justamente, en que la dimensión literaria del texto permite acrecentar sus valencias referenciales. Así, la representación de los campos de exterminio que ofrece Levi goza de una concretitud, precisión y exactitud que son alcanzadas, justamente, gracias a su lenguaje figural.

White emplea la noción de literatura testimonial para describir la obra de Levi, pero la amplía con el fin de incluir otro tipo de escritos que, si bien no intentan narrar una experiencia efectivamente vivida, sí logran presentar una imagen realista de cómo debe de haber sido un momento y lugar del pasado. Esas ficciones realistas ${ }^{1}$ exploran "la línea que divide lo real de ese tiempo y espacio de lo que los historiadores reconocerían como las verdades que conocemos

\footnotetext{
${ }^{1}$ Uno de los ejemplos de White es la novela Mrs. Dalloway, de Virginia Woolf, que ofrece una imagen realista de cómo debe de haber sido Londres en 1920. También se nombra la literatura modernista de autores como Proust, Joyce, Musil, etc. (WHITE 2010a).
} 
acerca de él" (WHITE 2010a, p. 170, cursivas mías). Esa distinción entre lo real -en tanto dominio del discurso ficcional- y lo verdadero -en tanto dominio de la historia - es central para comprender las posibles contribuciones de la literatura al estudio del pasado. Lo real supone y trasciende lo verdadero, ya que incluye no sólo todo aquello que puede ser dicho verazmente sobre lo que fue, sino también todo aquello que puede ser dicho verazmente acerca de lo que posiblemente podría haber sido.

Hay un último elemento que White recupera de la literatura de Levi que resulta particularmente relevante para este artículo: el abanico emocional que sus textos evocan. La obra de Levi, cargada de emociones, afectos y dolor, habilita el acceso a un "rango de sentimientos inducido por la experiencia de una condición histórica extraordinaria de sometimiento y humillación" (WHITE 2010a, p. 171). El punto clave es que no hay ningún conflicto entre esos elementos emotivos y poéticos y las funciones referenciales del texto de Levi, sino que, más bien, se complementan para formar una imagen cognitivamente eficaz del pasado.

Este artículo se apoya en esas consideraciones whiteanas con el fin de analizar las posibles contribuciones de las novelas de Roth y Cunningham para explorar la historicidad de cierta experiencia emocional. Pero, para alcanzar ese objetivo, se complementará la propuesta de White con algunos desarrollos teóricos recientes en torno a la relación entre historia y literatura y en torno a la idea de felicidad, provenientes del giro afectivo.

\section{El mapa afectivo como índice histórico}

En las últimas décadas, tanto desde el discurso histórico como desde los estudios culturales, han emergido nuevas aproximaciones teóricas cuyo eje central es el análisis de las emociones como fenómenos históricos y culturales.

La historia de las emociones, por un lado, retoma los desarrollos historiográficos de principios y mediados del siglo XX de Lucien Febvre, Johan Huizinga y Norbert Elias para justificar la importancia de centrarse en las emociones en la investigación histórica. Febvre, ya en 1941, había sugerido que las emociones eran contingentes e históricamente situadas y que la vida afectiva de antaño era tan diferente a la de nuestros días que su recuperación obligaba a los historiadores a abandonar todo prejuicio sobre la universalidad de la psique humana (MATT 2014).

Por su parte, el denominado "giro afectivo" en las humanidades parte de la historicidad de las emociones para cuestionar las posiciones teóricas -algunas de ellas provenientes de la psicología y la biología- que piensan los afectos como respuestas fisiológicamente predeterminadas a ciertos estímulos externos. El giro afectivo, de ese modo, hace estallar algunas de las dicotomías por medio de las cuales se han concebido tradicionalmente los estados afectivos: biológico/ cultural; exterior/interior; razón/pasión; entre otras.

Sara Ahmed, en particular, argumenta que tanto la perspectiva que considera que las emociones nacen del interior del sujeto y luego se expresan exteriormente como aquella que postula que las emociones son sociales y el 
individuo posteriormente las internaliza son erróneas. Ella busca ofrecer una teoría del funcionamiento afectivo que no presuponga ni un adentro ni un afuera, ni un yo ni un mundo dado. Más bien, para Ahmed, son las emociones, por medio de su circulación, las que van configurando y dando sentido al yo, al cuerpo y a los objetos con los que el cuerpo entra en contacto: "Mi análisis mostrará cómo las emociones crean las superficies y los límites que permiten delinear todo tipo de objetos. Los objetos de las emociones toman forma como efectos de circulación"2 (AHMED 2010, p. 10). Según Ahmed, los objetos transitan por el espacio social y en esa circulación se van saturando de afectos determinados. Los objetos no son intrínsecamente asquerosos, agradables, temibles, odiosos o felices; más bien, devienen tales en virtud del sentido que adquieren en la circulación social. Los afectos, así, corren el riesgo de convertirse en fetiches, "cualidades que parecen residir en objetos, sólo por la borradura de la historia de su producción y circulación" (AHMED 2010, p. 11).

A partir de ese marco teórico, se podría afirmar que las emociones no son un mero epifenómeno del contexto histórico, sino agentes responsables de la producción y transformación de ese contexto y de las subjetividades que lo componen. $\mathrm{O}$, dicho en otras palabras, que no sólo las emociones varían históricamente, sino que el devenir histórico mismo trabaja a través de las emociones, estructurando el mundo compartido y produciendo las ataduras afectivas que nos constituyen como sujetos históricos.

Ahora bien, ¿en qué sentido la literatura puede aportar a la tarea de comprender 160 la historicidad de las emociones? Como se expuso cuando se reseñó la filosofía de la historia de White, la literatura puede ser un ámbito sumamente valioso para examinar el rango de sentimientos que despierta cierta experiencia histórica. En ese sentido, podríamos pensar la ficción realista como mapas afectivos, en el sentido técnico que Jonathan Flatley desarrolla: "'Mapa afectivo' es el nombre que le doy a una tecnología estética -en el sentido más antiguo y básico de technéque representa la historicidad de la propia experiencia afectiva" (FLATLEY 2008, p. 4). El mapa afectivo remite a una serie de estrategias estéticas que nos permiten percibir la vida emocional de los sujetos como cristalizaciones de procesos institucionales. Flatley, cuyo tema de análisis es la melancolía, retoma a Walter Benjamin para afirmar que ese mapa afectivo nos permite conectar nuestra vida emocional con los procesos históricos y, de esa forma, percibir cuánto hace que nuestra miseria estaba en preparación. A su vez, permite entendernos como una comunidad de melancólicos al vincular el mundo afectivo personal con una matriz social más amplia que produce otras experiencias en sintonía con la propia. Flatley añade que los mapas afectivos son máquinas de autoextrañamiento, en la medida en que habilitan la "desfamiliarización, hacer que la propia vida emocional - los rangos de emociones, las estructuras de sentimientos y el conjunto de las ataduras afectivas- parezca extraña, sorprendente, inusual" (FLATLEY 2008, p. 80). 
La propuesta de Flatley, de ese modo, permite vincular las estrategias estéticas de la ficción realista con la atmósfera afectiva que excede la experiencia de un sujeto particular. La noción de atmósfera afectiva -o Stimmung, en términos heideggerianos - remite a estados de ánimo en los cuales se forman intenciones, se persiguen proyectos y ciertos afectos se adhieren a objetos particulares. Siguiendo a Heidegger, Flatley sostiene que la Stimmung no puede ser considerada una experiencia personal, interna o psicológica, sino que es colectiva, pública e inevitablemente compartida. Los estados de ánimo no están en nosotros, nosotros estamos en ellos. Así, Flatley argumenta que la depresión, por ejemplo, puede ser considerada una atmósfera afectiva en la medida en que media la forma en que nos interesamos (o desinteresamos) por el mundo. Cuando ese estado de ánimo adquiere especificidad histórica, Flatley lo denomina estructura de sentimientos, siguiendo la clásica formulación de Raymond Williams. Si la depresión es una Stimmung, dirá Flatley, la depresión de los campesinos rusos en los años 1920 es una estructura de sentimiento.

En los próximos apartados, se busca analizar un tipo particular de estructura de sentimiento representada en las novelas Pastoral Americana y Flesh and Blood que emerge a fines de los años 1960 a la luz del desencantamiento respecto a la fantasía del sueño americano. En ambas novelas aparece una demanda de los padres hacia los hijos basada en una idea de felicidad que deja de operar como lazo de cohesión familiar. "Felicidad", palabra que se repite innumerables veces en ambos libros, designa no tanto un estado afectivo experimentado por los personajes, sino, más bien, una promesa siempre postergada, un horizonte al que nunca se arriba, o bien porque está anclada en un pasado que ya no volverá, o bien porque apunta a un futuro que parece desobedecer todo intento de dominarlo.

La noción de promesa de felicidad, que es desarrollada por Ahmed en su obra homónima, es útil para pensar, en primer lugar, la temporalidad de la felicidad $y$, en segundo lugar, las clases de objetos y sujetos que aparecen asociados legítimamente a ella.

Con respecto a la temporalidad, Claire Colebrook señala que la felicidad humana se caracteriza por tener significado y que ese significado, la capacidad de las personas de organizar su mundo, es lo que le permite al organismo mantenerse a sí mismo en el tiempo. "El presente se torna significativo o feliz sólo por la promesa del futuro, un futuro que puede ser anticipado sólo como el fin del yo" (COLEBROOK 2007, p. 88). Ese futuro, de acuerdo con Ahmed, intenta ser dominado por ese yo mediante la consecución de ciertas acciones que nos prometen felicidad. La felicidad, de esa forma, no es considerada como algo que meramente nos sucede de casualidad o por suerte, sino como el resultado de actos intencionales que llevamos a cabo con vistas a la vida feliz.

Eso nos permite avanzar hacia el segundo punto: no todas las personas, objetos y eventos nos prometen felicidad de igual forma ni merecen la felicidad de igual forma. Lo interesante es que ese conjunto de objetos felices acumulan valor afectivo incluso en situaciones de gran infelicidad; por ejemplo, en el caso de padres que experimentan el fracaso de la promesa de felicidad $y$, sin 
embargo, continúan proyectando esa promesa en sus hijos (un tema recurrente en ambas novelas).

Según Ahmed, existe un archivo de felicidad en la historia occidental que incluye una serie de ideas, creencias, narrativas, imágenes e impresiones sobre qué es la felicidad. En oposición a ese conglomerado, también existe una serie de historias sobre aquellos que están exiliados del terreno de la felicidad hegemónica. Ese archivo de infelicidad - que Ahmed ilustra con las figuras de la feminista aguafiestas, el inmigrante melancólico, las personas queer infelices, entre otros- está formado por quienes eligen no cargar sobre sus hombros la deuda de la felicidad que otros les heredan.

Pero ¿qué significa que la felicidad sea una deuda? Ahmed sostiene que frases habituales como "sólo quiero que seas feliz" o "soy feliz si tú eres feliz" ponen en evidencia el carácter condicional de la felicidad: la felicidad de una persona es la condición necesaria de la felicidad de otra. Esas frases también visibilizan el carácter social de la felicidad, que se podría resumir, a su vez, con esta frase: "tu sentimiento es el objeto de mi sentimiento y me rehúso a ser feliz si la felicidad no puede ser compartida". El problema es que los términos de la condicionalidad son desiguales y que la felicidad de algunas personas tiene primacía por sobre la de otras. En el marco familiar, por ejemplo, "El niño tiene un deber de felicidad. Ese deber puede funcionar como deuda, una forma de devolver lo que debe" (AHMED 2010, p. 59). Heredar una familia, en ese sentido, puede significar heredar la demanda de reproducir sus formas y su ideal de vida feliz. Esa herencia supone que la felicidad de los hijos implica continuar la vida de sus padres, vivir la vida que ellos ya vivieron o, incluso, vivirla mejor. "Si la crianza implica orientar al niño de forma correcta, los niños deben localizar sus deseos de felicidad en las mismas cosas. La familia se convierte en un objeto feliz si compartimos esa orientación" (AHMED 2010, p. 48). De esa forma, la familia aparece como sujeto y objeto de la felicidad y la vida feliz implica la repetición de las formas de la comunidad afectiva.

Los archivos de infelicidad están repletos de hijos que se niegan a acomodarse en el engranaje familiar, aquellas ovejas negras que no sólo arruinan su propia vida, sino también la de sus padres al destrozar la condicionalidad de la felicidad. En los apartados que siguen, se estudiarán dos novelas que pueden engrosar los archivos de infelicidad de Ahmed revelando una estructura de sentimiento basada en el rechazo de la deuda de felicidad heredada.

\section{Pastoral Americana: la caída del héroe americano}

La novela Pastoral Americana narra la historia de Seymour Levov o el Sueco, un exitoso comerciante judío de Newark quien parece ser la máxima personificación del sueño americano. El Sueco es presentado desde la perspectiva de Nathan Zuckerman, el narrador y protagonista de la novela, quien lo recuerda como su héroe de la infancia. Zuckerman, quien se convierte en escritor, recibe muchos años después una carta del Sueco donde le transmite su deseo de escribir la trágica historia de su padre. Lo que atrae a Zuckerman no es tanto la oportunidad laboral, sino saber qué desgracias pudieron haberle 
acontecido a un personaje que, en la memoria del narrador, adquiere un estatus casi mítico.

Cabe aclarar que su admiración desmedida no era excepcional. El Sueco representaba, en el período de posguerra estadounidense, el ídolo de toda la comunidad judía de Newark en virtud de sus logros como estrella deportiva de los equipos de baloncesto, béisbol y fútbol americano del colegio. Lo fascinante del Sueco, en especial para sus compañeros de escuela, era su isomorfismo con la vida WASP, ${ }^{3}$ el hecho de ser un judío que triunfó no a causa de proezas intelectuales -como el resto de los judíos exitosos-, sino haciendo aquello que los jóvenes americanos típicos hacían para triunfar. Lo extraordinario de su éxito radicaba, justamente, en su carácter ordinario.

Las equivalencias discursivas entre Levov y Estados Unidos pueblan la novela de Roth. Idolatrar al Sueco, para la colectividad, significaba idolatrar a Estados Unidos, lo cual implicaba cierta cuota de vergüenza y rechazo hacia el propio judaísmo:

¿Dónde estaba el judío en él? No podías localizarlo y, no obstante, sabías que estaba allí. ¿Dónde estaba la irracionalidad? ¿Dónde la tendencia a lloriquear? ¿Dónde las tentaciones descarriadas? En él no había astucia ni artificio ni malicia. Había eliminado todo eso para lograr su perfección (ROTH 2007, p. 35).

Así, la novela va delineando aquellos rasgos que deben ser exorcizados para poder abrazar el ideal de vida buena asociado al sueño americano.

Las imágenes de la memoria del narrador, envueltas en múltiples capas de idolatría y fantasía, remiten a una primera caracterización de la felicidad, la felicidad añorada de la juventud en el período de posguerra estadounidense: "Nuestro curso dio comienzo en la escuela de enseñanza media seis meses después de la rendición incondicional de los japoneses, en el apogeo de la mayor embriaguez colectiva en la historia norteamericana" (ROTH 2007, p. 59). También apuntan a una primera noción de mandato intergeneracional, aquella que exhorta a los jóvenes a aprovechar al máximo las posibilidades que les ofrece el presente y realizar, en el futuro, aquello que sus padres no pudieron realizar en el pasado:

Por si la milagrosa conclusión de aquel imponente acontecimiento [...] no fuese lo bastante inspiradora, estaba el barrio, la determinación vecinal de que nosotros, los niños, nos libráramos de la pobreza, la ignorancia, la enfermedad, los agravios sociales y la intimidación, que nos libráramos, por encima de todo, de la insignificancia (ROTH 2007, p. 60).

La felicidad, en la novela, se presenta de modo fantasmal. Por un lado, es una sensación que mora en un pasado idealizado. En ese sentido, el título de la primera parte de la novela, "Paraíso recordado" (a la que le siguen dos partes más, "La caída" y "Paraíso perdido"), es sugerente en tanto remite a la ausencia de una ausencia: hay algo que se ha perdido - el paraíso- y que 
sólo podemos añorar, pero ese paraíso, más que una verdad, también posee un carácter ideal. El paraíso, como la felicidad, es algo que opera en el plano de la fantasía, si bien también se materializa en la forma de un horizonte y de una demanda: el pedido de la comunidad de empuñar las oportunidades. La fuerza histórica de ese pedido termina vaciando toda rebeldía que pudiera existir en los hijos de inmigrantes judíos: "Habría sido necesario mucho más valor (o tal vez necedad) del que la mayoría de nosotros éramos capaces para decepcionar sus apasionadas e incansables ilusiones sobre nuestra perfectibilidad" (ROTH 2007, p. 61). Como se verá más adelante, la generación posterior no tendrá el mismo recaudo a la hora de evadir la exigencia familiar.

El Sueco es la figura que mejor encarna esa demanda de perfectibilidad: hace una estadía en el ejército, se casa con Miss Nueva Jersey, tiene una hija, compra la casa de sus sueños y conduce la empresa familiar al éxito. Sin embargo, tal como Zuckerman averigua tras conversar con su hermano, el Sueco, en realidad, es la máxima figura de la tragedia, aquel quien, a pesar de hacer todo bien, cosecha sólo el mal: "La tragedia del hombre que no está hecho para la tragedia..., ésa es la tragedia de cada hombre" (ROTH 2007, p. 114).

En la cena con el Sueco, Zuckerman reconoce rápidamente que su viejo ídolo no tiene intenciones de desplegar su miseria y que lo único que puede hacer es dar un listado de sus éxitos, su alegría familiar y los logros de sus hijos (provenientes de su segundo matrimonio). De esa cena, el narrador sale desencantado: aquel semidiós de la niñez se había convertido en el más banal y superficial de los hombres. Zuckerman intentó en vano penetrar la fachada que el Sueco exhibía, pero debajo de la superficie sólo encontraba más superficie. Levov se había convertido en aquel hombre ordinario y decente que vivía la vida que cualquier norteamericano querría vivir.

Es aquí donde aparece una segunda constelación semántica en torno a la felicidad: la vida feliz como un signo de mediocridad y conformismo. El narrador incluso se pregunta si el Sueco no se habrá vuelto loco; finalmente, reconoce que,

tal vez era, sencillamente, un hombre feliz. También hay personas felices. ¿Por qué no habrían de existir? Tanta especulación dispersa sobre los motivos del Sueco se debía tan sólo a mi impaciencia profesional, mi intento de imbuir al Sueco Levov algo parecido al significado tendencioso que Tolstoi asignó a Iván Ilich (ROTH 2007, p. 48).

La comparación entre Ilich y Levov es central. La vida de Ilich, el hombre corriente y ordinario menospreciado por Tolstoi, es descrita por el escritor ruso como habiendo sido "de lo más sencillo y ordinario y, por lo tanto, de lo más terrible". Zuckerman entiende que ese podría haber sido el caso de la Rusia de 1886, pero, para un judío de Nueva Jersey, "La vida del Sueco Levov, que yo supiera, había sido de lo más sencillo y ordinario y, por lo tanto, espléndida, totalmente acorde con el carácter norteamericano" (ROTH 2007, p. 48, las cursivas de Roth). La asociación entre el sueño americano, el conformismo, la vida feliz y los deseos de asimilación de los hijos de inmigrantes judíos parece materializarse en la figura del Sueco.

No obstante, esa armonía se rompe con la tragedia que sofocó los sueños 
de los Levov. La figura de la caída de la felicidad del Sueco es Merry, la única hija de su primer matrimonio. Merry -que, en inglés, significa "alegre"- es, irónicamente, quien obtura la alegría familiar al negarse a cargar sobre sus hombros la deuda de felicidad que le dona su familia. Merry viola la condicionalidad de la felicidad y le roba al Sueco la vida que se merece.

Merry fue criada como la hija única de un matrimonio perfecto, guarecida por las comodidades de una clase media obsesionada por personificar el sueño americano. No obstante, en 1968, la hija tartamuda, obesa e iracunda pone una bomba en la oficina de correo de Newark y termina asesinando a una persona. El acto terrorista de Merry desata en la novela una serie de tensiones entre la felicidad y la infelicidad; entre la fantasía y la realidad; y entre la necesidad y la contingencia. Por un lado, la rebeldía de Merry - quien, en su adolescencia, empieza a militar contra la Guerra de Vietnam - no se dirige únicamente hacia las políticas bélicas de los Estados Unidos, sino también hacia el modelo de familia que sus padres representan. Merry se niega a ser una pieza más en el engranaje perfecto de los Levov. En palabras del tío, Merry es "[la] hija huida que debía haber sido la imagen perfeccionada de sí mismo, de la misma manera que él había sido la imagen perfeccionada de su padre y éste la imagen perfeccionada de su abuelo" (ROTH 2007, p. 113). Así se hace presente un tema que aflorará también en Flesh and Blood: las proyecciones que los familiares arrojan sobre su prole, la esperanza de que las próximas generaciones sigan subiendo la escalera del éxito ya abordada por las anteriores.

La equivalencia entre la familia Levov, la americanización y la buena vida - un entramado que el Sueco había tejido de manera casi perfecta- es lo que Merry rechaza. "A Seymour le gustaba el tipismo norteamericano, pero a la chica no. Él la sacó del tiempo real y ella le hizo volver del todo a la realidad" (ROTH 2007, p. 93). Aquí aparece nuevamente el carácter irreal de la felicidad, su estatus fantasioso, su materialización imposible. El verdadero acto terrorista de Merry no es estallar la oficina postal, sino bombardear la pastoral americana que sus padres añoraban, no tanto para ellos mismos sino, en especial, para ella: "Fue como si la bomba hubiera estallado en su sala de estar" (ROTH 2007, p. 95-96).

La novela es particularmente exitosa en diagramar la tensión entre necesidad y contingencia que subyace a la felicidad. Tal como lo señala Ahmed, la promesa de felicidad puede ser vista como una promesa contra los imprevistos. Ahmed retoma la etimología de la palabra "felicidad" en inglés - happiness- para mostrar cómo, en un principio, el término estaba vinculado a la buena suerte - good hap- y que ser feliz implicaba necesariamente una dosis de buena fortuna. Ese significado hoy nos parece arcaico, ya que "estamos acostumbrados a pensar en la felicidad como un efecto de lo que uno hace, como un premio por el trabajo arduo, más que como algo que 'simplemente' nos sucede [happens]" (AHMED 2010, p. 22).

En Pastoral Americana, el deseo de encontrar un antídoto contra las contingencias se cristaliza en el Sueco. La fidelidad a las normas y a las convenciones operan, para él, como una barrera contra lo improbable. Zuckerman 
reconoce eso cuando se juntan a cenar: "Era como si hubiese abolido de su mundo cuanto no le convenía, no sólo el engaño, la violencia, la burla y la crueldad, sino todo cuanto presentaba la menor aspereza, cualquier amenaza de contingencia" (ROTH 2007, p. 55). La enseñanza brutal de Merry es la de que los resultados de la obediencia no pueden ser dominados:

Había aprendido la peor de las lecciones que puede dar la vida: la de que carece de sentido. Y cuando sucede tal cosa, la felicidad nunca vuelve a ser espontánea, sino que es artificial e, incluso entonces, se compra al precio de un obstinado distanciamiento de uno mismo y de su historia (ROTH 2007, p. 108).

En esta cita se evidencia la máquina de extrañamiento descrita por Flatley. La felicidad pierde su carácter espontáneo y se revela como lo que siempre fue: un artificio, una ficción para ordenar el mundo y hacer de la contingencia algo más controlable. La acción de Merry, a su vez, nos permite reconocer la incapacidad que tienen las personas como el Sueco de enfrentar aquello que creían haber exorcizado de su vida. El Sueco no se resigna a aceptar la contingencia e intenta buscar posibles causas que expliquen el accionar de su hija. Se pregunta si se convirtió en un monstruo a causa de su tartamudeo, de su gordura o como resultado de un beso que el Sueco le dio, intentando tranquilizar un ataque de tartamudeo, cuando ella tenía sólo 12 años. Sin embargo, cuando el psicólogo que visita a su hija intenta hacerle entender que, quizás, los problemas fónicos de Merry estén directamente relacionados con el ser parte de una familia perfecta que sobrevalora cada palabra que sale de su boca, él no lo quiere escuchar. Tal como reaparecerá en Flesh and Blood, si hay algo que no es fácil para los padres es abandonar los ideales que han guiado sus vidas, incluso cuando los efectos de la persecución de esos ideales sean los opuestos a los prometidos.

\section{Flesh and Blood: cien años de miserias}

La novela de Cunningham trascurre de 1935 a 2035 y se centra en la historia de los Stavos, una familia de inmigrantes - padre griego, madre italiana- que se establece en Long Island.

El tema de la novela es, nuevamente, los efectos poco felices de la promesa de felicidad, las decepciones que los hijos acarrean a sus padres y las libertades que las nuevas generaciones se permiten conquistar. El epígrafe de Gertrude Stein - cita de The Making of Americans - con el que se inicia la novela es, en ese sentido, sugerente: "Una vez un hombre enojado arrastró a su padre por el suelo de su propio huerto. 'iDetente!' gritó, finalmente, el viejo. 'iDetente! Yo no arrastré a mi padre más allá de este árbol'" (apud CUNNINGHAM 2007, p. 1). Lo interesante de esta cita es que el viejo no le pide al hijo que no lo desafíe, sino, paradójicamente, que lo haga sin violar la tradición. No se cuestiona que los hijos tengan que enfrentar al padre; lo que se objeta es que ese enfrentamiento se dé por fuera de los límites trazados por la historia familiar. Esa demanda paradójica reaparece constantemente en Flesh and Blood, ya que, si bien el 
padre, Constantine, deja Grecia para comenzar una nueva vida en Estados Unidos, no puede soportar que sus hijos, en especial el varón, elijan otro camino.

En esta novela aparece, quizás con mayor fuerza que en Pastoral Americana, la proyección que los padres arrojan sobre su prole. De los tres hijos, la mayor, Susan, es quien reproduce más fielmente el modelo familiar -y quien también reitera con mayor fidelidad la infelicidad doméstica-, mientras que los dos hijos menores, Billy y Zoe, desarrollan estilos de vida totalmente inaceptables.

Zoe es la hija extraña, mística, salvaje, que ninguno de los padres comprende y que no es reconocida como la favorita de ninguno de ellos (Constantine prefiere a Susan y Mary, la madre, prefiere a Billy). Volviendo sobre los peligros de la americanización incompleta, Constantine sospecha que el problema de Zoe es que le pusieron el nombre de su abuela griega en vez de optar por un nombre estadounidense. Zoe abandona la casa paterna en Garden City para irse a vivir a Nueva York a principios de la década de los años 1970. Se junta con las travestis de los bares, consume todo tipo de drogas y tiene sexo ocasional con cualquier hombre. Zoe está fascinada por los peligros de Nueva York como de niña estaba fascinada por la vida en el bosque. Zoe es presentada como una figura de la animalidad y de los placeres de la vida salvaje. Ella queda embarazada y tiene un hijo mestizo. También se contagia el HIV y termina sus días tal como los vivió: siendo testigo (y no protagonista) de la vida familiar, dándose cuenta de relaciones y secretos que otros no podían ver.

Si bien Zoe es una de las figuras de la huida familiar, especialmente a causa del nieto que engendra - "el pequeño bastardo negro", tal como lo llama Constantine- son probablemente Billy y Susan los que conforman los contrastes más interesantes de la novela.

Billy se presenta como un chico delicado, femenino, endeble, interesado por la lectura, buen estudiante $y$, a causa de todo lo anterior, el blanco favorito de la ira de su padre. Billy, desde su corta infancia, despierta una furia en su padre que suele culminar en todo tipo de maltrato físico. El hijo encuentra placer en desafiar al padre, en hacerle notar que es más inteligente que él y en ostentar que no hay nada de Constantine que él quisiera recuperar para sí.

En la novela, no sólo la felicidad familiar es un tema problemático, sino también el amor. En varias ocasiones, los padres se repiten a sí mismos que deben amar a sus hijos, que no puede ser posible que no los amen. Eso es especialmente así en los casos en que se comparte el género y aparecen las exigencias propias de la masculinidad y la feminidad: Constantine se ve obligado a convencerse de que ama a Billy (y Mary hace lo propio con Susan). En un momento, al ver a su hijo adolescente con una camisa floreada, Constantine reflexiona: "Sabía que amaba a su hijo - ¿qué clase de hombre no lo hace?pero quería que fuera diferente" (CUNNINGHAM 2007, p. 108). La novela pone en primer plano un tema central del psicoanálisis: el vínculo entre el amor y el narcisismo, en tanto el amor por el hijo se ve supeditado a que el hijo repita aquello que fue su padre. Ese deseo de vivir nuevamente a través del hijo se hace evidente cuando Constantine empieza a tener una amante y reconoce, orgullosamente, que está tan excitado como cuando tenía quince años: "Podría 
haber sido su propio hijo, el hijo que siempre quiso" (CUNNINGHAM 2007, p. 170). La duplicación de la vida del padre en la de sus hijos es reflexionada por Constantine desde la diferencia de género:

Cuando Mary dio a luz a un hijo, Constantine se imaginó a sí mismo tomando puñados del futuro y metiéndoselos en su boca. Las hijas, incluso las mejores, desaparecen en la vida de los hombres. Pero un hijo te lleva consigo. Sus placeres incluyen a los tuyos; vivís en tu piel y también vivís en la de él (CUNNINGHAM 2007, p. 168).

Pero Constantine no quiere vivir en la piel de Billy porque sabe, incluso antes de que su hijo salga del closet, que el puñado de futuro que metió en su boca fue escupido por él. Si bien encuentra cierta afinidad con Billy, al reconocer que está haciendo lo mismo que él hizo al emigrar, es el modo en el que el joven se aliena de su familia lo que le resulta inaceptable. Efectivamente, Billy quiere volverse un extraño. Se cambia el nombre por Will, se va a estudiar a Harvard y se convierte en docente porque es la profesión más lejana a su padre que puede encontrar: "Will sólo quería una cosa: ser un extraño para su familia. Desaparecer", sin embargo, el autor también nos recuerda lo difícil de esa alienación: "Ya no pertenezco a esta familia pero no puedo encontrar una forma de irme tampoco" (CUNNINGHAM 2007, p. 164-166).

Quien sí halla una forma de irse es Susan. De hecho, su reproducción del formato familiar tiene como fin romper los vínculos con los Stavos: "Quería una familia propia. Cuando ella y Todd tengan un hijo, estarían separados, completos [...]. Ya no visitaría a sus familias en las fiestas" (CUNNINGHAM 2007, p. 132). Las diferencias entre Susan y Billy se hacen evidentes desde pequeños y son notadas, cuando no reforzadas, por sus padres. Susan es quien defiende al padre tras su maltrato a Billy, quien regaña a los hermanos cuando se portan mal, la que sigue todas las reglas y se sabe poderosa al encarnar todos esos atributos.

Constantine prefiere a Susan sobre los otros hijos e incluso sobre Mary y, secretamente, desea que su mujer se parezca más a ella. Tras mudarse a una nueva y más cara casa, Susan se da cuenta de "que el padre había comprado todo esto para ella. Se sentía halagada y asustada" (CUNNINGHAM 2007 , p. 35). Esos sentimientos encontrados se profundizan cuando ella y el padre comienzan una rutina de besos y abrazos incestuosos. Todo arrancó una noche en la que él había regresado borracho, tras haberse peleado con Billy. Ella tomó la cara del padre y lo besó y, después, ya no supo cómo decir que no. El acto atormenta tanto al padre como a Susan y la frase "eran sólo besos y abrazos" se repite incesantemente en los pensamientos de ambos con el correr del tiempo. Con Susan aparece nuevamente la duplicación deseada por Constantine: "Él era ella, en cierta forma, y ella era él" (CUNNINGHAM 2007, p. 244), pero, a diferencia de lo que ocurre con el hijo, esa identificación se resuelve sexualmente.

La única forma que Susan encuentra para salir de ese círculo incestuoso es casándose con su novio de la secundaria. Sin embargo, ese acto de ruptura 
con el padre la vuelve incluso más perfecta ante sus ojos y, cuando Constantine piensa en la felicidad y la buena vida, la imagen que le viene a la mente es la de la nueva familia de Susan. "Mientras Constantine se servía otro trago, pensó en Susan, valiente e inteligente e indulgente, moviéndose fluidamente y con seguridad hacia un futuro que aguarda sólo mejores y mejores noticias" (CUNNINGHAM 2007, p. 110). La idea de felicidad está atada a Susan, a aquella hija que logra trascender la familia no convirtiéndose en una extraña, sino en una versión superior del formato familiar mismo.

En Flesh and Blood, si hay algo voluble, ausente y fantasmático es, justamente, la felicidad. Mary nunca es completamente feliz y todas las escenas domésticas a las que ella parece pertenecer - fiestas, cumpleaños, reunionesdemuestran que la felicidad es un disfraz que debe ponerse para la ocasión. Constantine, por su parte, se siente feliz cuando arriba a su casa: "Lleno de felicidad, entró el auto al garaje" (CUNNINGHAM 2007, p. 43); no obstante, esa sensación desaparece a medida que baja del auto e interactúa con su familia. Él sabe cómo debe ser feliz - en el seno familiar, junto a los suyos-, pero el ser y el deber ser no coinciden.

Si la felicidad experimentada es efímera, la felicidad como deseo es una constante. Constantine, "Quería ser feliz de forma sólida y sostenible, hora a hora, no a través de ataques turbulentos que le acaecían en momentos extraños, usualmente cuando estaba solo" (CUNNINGHAM 2007, p. 44). Y, más adelante, el autor remarca el carácter voluble y escurridizo de la felicidad: "La idea de Susan, como su felicidad y su rabia, volaron insolentemente alrededor de la habitación, negándose a asentarse donde sus sentimientos correctos habitaban" (CUNNINGHAM 2007, p. 111).

La felicidad, en tanto ausencia constantemente presente en la forma del anhelo y de la promesa, es la herencia que la familia dona a sus hijos y, posteriormente, a los hijos de sus hijos. Ni Jamal (el "pequeño bastardo negro") ni Billy ni Zoe son depositarios legítimos de esa felicidad (ni lo quieren ser). En cambio, Susan y Ben (el hijo que tiene con Todd) sí aparecen como los herederos privilegiados, en especial el último: "Aquí estaba el futuro que Constantine había trabajado por conseguir, en este niño fornido y afectuoso, con una mandíbula griega y ojos americanos bien separados" (CUNNINGHAM 2007 , p. 257). Lo sorprendente y cruel a la vez es que quienes mejor encarnan la fantasía familiar son quienes menos se acercan a la felicidad prometida. De hecho, Ben, el nieto perfecto, sufre porque es consciente de que hay algo malo en él, de que existen dos mitades contradictorias que luchan dentro de él y de que no siempre la buena mitad domina. Su familiar favorito es su abuelo y Ben sabe exactamente qué decir y qué hacer para hacerlo feliz. Con total conciencia de la condicionalidad de la felicidad y de la necesidad de demostrar signos de bienestar, Ben comprende lo que su familia espera de él y se esfuerza por entregar todo lo que ellos demandan.

El mal que habita en él es su deseo sexual por su primo Jamal. Una tarde en el bosque, cree que el abuelo los descubre en una situación amorosa y, para reparar el daño que eso le podría causar, le grita a Jamal "maldito maricón" lo 
suficientemente fuerte como para que su abuelo lo escuche. Como si la felicidad fuera un juego de suma cero, Ben sabe que, para salvarse, debe arruinar a Jamal, tiene que convertir a su primo en un extraño. Sin embargo, cuando más tarde se va a navegar con su abuelo y este lo llama "hijo", Ben no lo soporta y vuelca el bote. Tras la caída, el nieto comienza a nadar hacia el horizonte, huyendo de su abuelo y de su vergüenza. Cuando se hace de noche, Ben se deja hundir y muere ahogado. El gran acto de osadía que Susan se permite es, durante el funeral de su hijo y frente a todo el mundo, acercarse al padre, tomar su cara y besarlo en la boca, "hasta estar segura de que él supiera que no estaba perdonado" (CUNNINGHAM 2007, p. 453).

\section{Reflexiones finales: el quiebre de la comunidad afectiva}

En este artículo, se han explorado dos novelas que ponen en primer plano los conflictos en el seno familiar una vez que la fantasía de felicidad que guió la vida de los padres es rechazada por los hijos. Una vez que admitimos, tal como lo sostiene el giro afectivo, que los sentimientos no son meras respuestas individuales, sino emergentes históricos, podemos reflexionar sobre la (in) felicidad como índice de la estructura de sentimiento que opera como bisagra entre dos generaciones en los Estados Unidos de fines de los años 1960 y principios de los 1970. Si bien esa época ha sido considerada, tradicionalmente, como un período de conflicto, ruptura y novedad ideológica, en este artículo se buscó focalizar no tanto en el quiebre político que las nuevas generaciones producen, sino en su rechazo a cierto ideal de buena vida vinculado a la familia, la nación, la clase media y la heteronormatividad. Mientras que para los inmigrantes de principio de siglo XX el sueño americano funcionaba como faro organizador de la experiencia a futuro, la generación subsiguiente adopta una mirada más desencantada respecto a la fantasía que heredan de su familia. En ese sentido, las novelas nos permitieron avizorar el componente afectivo de una conciencia histórica rupturista.

Ahora bien, eso no significa que los padres sean felices y los hijos infelices. Por el contrario, al rechazar la condicionalidad de la felicidad, los hijos ponen en jaque la felicidad para todos, al mismo tiempo en que hacen evidente la poca capacidad adaptativa de los padres para incorporar nuevas fantasías de la buena vida. Si pensamos en la familia como una comunidad afectiva, los hijos rompen esa comunión al negarse a asumir como propio el objeto de deseo que sus padres quieren para ellos. Así, la contracara de la condicionalidad de la felicidad es que el deseo de bienestar para los hijos nunca es incondicional. Por eso, el clásico "soy feliz si tú eres feliz" es engañoso. Lo que se ve en las novelas es que los padres no pueden ser felices si sus hijos son felices con objetos que ellos jamás elegirían.

El ideal de felicidad, a pesar de todo, es difícil de ser abandonado, incluso cuando no genera un sentimiento efectivo de bienestar y cuando se presenta, a lo sumo, como una ausencia o como un anhelo. En ambas novelas se hace evidente lo que Ahmed denomina la lógica de aplazamiento que mueve a los padres a no abandonar sus fantasías de la buena vida: "uno puede seguir 
creyendo en la felicidad a pesar de las decepciones siempre y cuando puede desplazar esas esperanzas hacia otros" (AHMED 2010, p. 59). La familia no debe necesariamente cosechar la promesa de felicidad para que esta siga operando como ideal regulativo; basta con que la fantasía se postergue a futuro (a la vida de los hijos o, incluso, de los nietos).

De ese modo, las novelas ostentan no sólo la ruptura de la comunidad afectiva desencadenada por los hijos, sino también las limitaciones que los padres exhiben a la hora de renovar el inventario de rutas posibles hacia la felicidad. Claramente, no es lo mismo tener una hija terrorista que un hijo gay, pero ambos casos ilustran la incapacidad de los padres para actuar ante las decepciones acarreadas por sus hijos y ante el rechazo explícito de seguir reproduciendo el formato familiar.

Si bien las novelas permiten entrever la estructura de sentimientos de una situación histórica concreta, su valor excede el de ser meros índices de cambios sociales. Más bien, se puede pensar en las obras de Roth y Cunningham como máquinas estéticas de producción de saberes sobre un tema clave para el pensamiento occidental: la (in)felicidad. Las novelas nos ayudan a indagar no tanto en la esencia de la felicidad, sino en sus efectos, qué tipos de mundos emergen cuando se invoca la felicidad. Lo paradójico es que ambas narraciones ponen en primer plano los efectos poco felices de la felicidad, cómo la felicidad puede convertirse en una trampa para los personajes que la invocan. Hay dos elementos que aparecen en los textos que son centrales para explorar el mandato de felicidad: por un lado, sus asociaciones a valores específicos sobre la nación, la religión, la raza y el género y, por otro, su carácter de repelente contra las contingencias.

Con respecto al primer punto, ambos relatos demuestran que la felicidad no sólo se encuentra asociada a ciertos valores, sino también a la exclusión de otros. En Pastoral Americana, la metamorfosis del Sueco, que lo convierte de niño judío a ídolo americano, se logra por medio del vaciamiento de su judaísmo y de una mimesis con la forma de vida WASP. En Flesh and Blood, si bien la cuestión de la americanización también está presente, se enfatizan especialmente las forclusiones raciales y sexuales que hacen de la felicidad un objeto que circula de forma desigual. Asimismo, apunta al deseo de mismidad y repetición que yace en la demanda intergeneracional de felicidad. La naturaleza prometedora de la felicidad implica una dimensión de futuro, pero las proyecciones que aparecen en ambas novelas, lejos de abrirse a la contingencia del porvenir, reafirman el deseo paterno de que los hijos repitan los valores y creencias que apuntalan la herencia familia.

Eso puede ser vinculado a la noción de futurismo reproductivo que Lee Edelman asocia a la heteronormatividad, un tipo de lógica política conservadora cuyo fin es reafirmar una estructura y autenticar el orden social en nombre de los niños (futuros) que debemos proteger (EDELMAN 2004). La imagen del niño, "hecha a imagen y para la satisfacción de los adultos", está cargada de proyecciones que apuntan a una "insistencia en la mismidad que intenta restaurar un pasado Imaginario" (EDELMAN 2004, p. 21). El niño queer - 
así como el "pequeño bastardo negro"- se presentan como obstáculos a ese futurismo reproductivo obsesionado por la repetición de la mismidad. ${ }^{4}$

La insistencia en un futuro controlable nos remite al último punto que se busca rescatar de las novelas: la felicidad como antídoto contra los imprevistos. En boca de los padres, la demanda de felicidad que arrojan sobre sus hijos aparece como una forma de dominar aquello que, en los años 1960 y 1970, se presenta como un presente indómito y un futuro incierto. Como ya se ha señalado, la contingencia -el hap- presente en una noción previa de felicidad es abandonada una vez que la felicidad se concibe como algo que depende de las acciones intencionales humanas. Colebrook ejemplifica esa idea recordando el horror que genera el pensar que la felicidad es algo que viene de afuera: "La felicidad que se alcanza por medio de las drogas o la suerte no es felicidad en absoluto; la felicidad se gana como un signo esencial del poder de autonomía del yo" (COLEBROOK 2007, p. 96). La felicidad apuntala la ilusión de autonomía, marcando que si elegimos cierto camino y nos mantenemos dentro de sus límites, más cerca estaremos de concretizar la promesa. En Pastoral Americana, en especial, se hace añicos esa ilusión de control y dominio. El Sueco siguió el guión perfecto hacia la vida buena; sin embargo, lo que Merry le devuelve, su más trágica lección, es la contingencia e injusticia que acecha la vida, que al input de decisiones adecuadas no le corresponde necesariamente un output de felicidad.

En cierto sentido, esta es la moraleja cruel que los hijos de ambos relatos nos dejan: la imposibilidad de controlar el devenir, la futilidad de la demanda

172 de reproducción de lo mismo, los imprevistos que hacen estallar la promesa de felicidad y el sentido de autonomía. El desafío tácito que plantean las novelas es qué hacer con los escombros de los sueños fracturados y cómo seguir habitando universos posibles una vez que el desgaste de una fantasía abra el espacio para nuevas formas de vida a futuro.

\section{Referencias bibliográficas}

AHMED, Sara. The Promise of Happiness. Durham; Londres: Duke UP, 2010. BERLANT, Laurent. Cruel Optimism. Durham; Londres: Duke UP, 2011.

CUNNINGHAM, Michael. Flesh and Blood: a Novel. New York: Picador, 2007. COLEBROOK, Claire. Narrative Happiness and the Meaning of Life. New Formations, v. 63, n. 1, p. 82-102, 2007.

EDELMAN, Lee. No Future: Queer Theory and the Death Drive. Durham; Londres: Duke UP, 2004.

FLATLEY, Jonathan. Affective Mapping: Melancholia and the Politics of

\footnotetext{
${ }^{4}$ El miedo al hijo homosexual en Flesh and Blood nos reenvía, nuevamente, a su historicidad, ya que remarca la imposibilidad que tiene un hombre gay para reproducir la vida familiar tipo en la era previa a las demandas de matrimonio entre personas del mismo sexo. $\mathrm{Si}$, como lo afirma Heather Love, la homonormatividad del siglo XXI modificó la experiencia de felicidad de las comunidades LGBT, esta novela nos habla de un momento en el que la fantasía de matrimonio, familia y vida feliz no tenía el grado de accesibilidad para las personas gays que tiene en la actualidad (LOVE 2007).
} 
Modernism. Cambridge; Massachusets; Londres: Harvard UP, 2008.

LOVE, Heather. Compulsory Happiness and Queer Existence. New Formations, v. 63, n. 1, p. 52-64, 2007.

MATT, Susan. Recovering the Invisible. Methods for the Historical Study of the Emotions. In: ; STEARNS, Peter (eds). Doing Emotions History. Urbana; Chicago; Springfield: Univ. of Illinois Press, 2014, p. 41-53.

ROTH, Philip. Pastoral Americana. Buenos Aires: De Bolsillo, 2007.

WHITE, Hayden. Teoría literaria y escrito histórico. In: El texto histórico como artefacto literario y otros escritos. Buenos Aires: Paidós, 2003, p. $141-188$.

. Ficción histórica, historia ficcional y realidad histórica. In:

Ficción histórica, historia ficcional y realidad histórica. Buenos Aires: Prometeo, 2010a, p. 169-182.

. En contra del realismo histórico: una lectura de La Guerra y la paz. In: Ficción histórica, historia ficcional y realidad histórica.

Buenos Aires: Prometeo, 2010b, p. 95-119. 